\title{
INHALED NITRIC OXIDE CONTRIBUTES TO LUNG REPAIR IN PIGLETS WITH ACUTE RESPIRATORY DISTRESS SYNDROME VIA INCREASING CIRCULATING ENDOTHELIAL PROGENITOR CELLS
}

\author{
Y. Qi, L. Qian, B. Sun \\ Departments of Pediatrics, Children's Hospital of Fudan University, Shanghai, China
}

Background and aims: No effective treatment currently exists for acute respiratory distress syndrome (ARDS). Nitric oxide (NO) plays an important role in endothelial progenitor cells (EPCs) mobilization. We hypothesized that inhaled NO (iNO) would induce EPCs mobilization and therefore promote lung repair.

Methods: Healthy piglets were randomized into four group $(\mathrm{n}=6)$ : Con, mechanical ventilation only; ARDS, ARDS was established by intravenous infusion of oleic acid and mechanically ventilated; G-CSF, ARDS plus G-CSF $(10 \mu \mathrm{g} / \mathrm{kg})$; iNO, ARDS plus NO inhalation(10 ppm), followed by EPCs detection, biophysical at different time (Baseline, $0 \mathrm{~h}, 24 \mathrm{~h}, 72 \mathrm{~h}$ and 7 days) and assessment of injury reparation at day 7.

Results: Compared with those in Con, the levels of EPCs increased in bone marrow but not in blood in ARDS animals at $24 \mathrm{~h}$. Inhaled $\mathrm{NO}$ induced rapid elevation of CD34+KDR+, KDR+CD133+ and CD34+KDR + CD133 + EPCs number in blood compared with $\operatorname{ARDS}(2163 \pm 454$ vs. $1094 \pm 416,1302 \pm 413$ vs. $429 \pm 244,1140 \pm 494$ vs. $453 \pm 273$ cells $/ \mathrm{ml}$, respectively, $\mathrm{P}<0.05)$, reduced the percentage of $\mathrm{KDR}+\mathrm{CD} 133+$ cells in bone marrow. The expression of lung CD34, CD133, VEGF, VEGF receptor 2 and endothelial nitric oxide synthase augmented in iNO but not in G-CSF compared with ARDS. iNO reduced vascular permeability, increased pulmonary vessel density, alleviated pulmonary edema and inflammation compared with ARDS. Plasma VEGF(478 \pm 63.3 vs. $256 \pm 81.1 \mathrm{ng} / \mathrm{l}$; P $<0.05)$, SDF-1 and NO level in bone marrow elevated in iNO compared with ARDS at $72 \mathrm{~h}$.

Conclusions: We conclude that iNO can mobilize EPCs from bone marrow into circulation, contribute to vascular repair and alleviate lung damage. 